\title{
Fiber Refractometer Based on a Fiber Bragg Grating and Single- Mode-Multimode-Single-Mode Fiber Structure
}

\author{
Qiang wu \\ Technological University Dublin, qiang.wu@tudublin.ie \\ Yuliya Semenova \\ Technological University Dublin, yuliya.semenova@tudublin.ie \\ Binbin Yan \\ Beijing University of Posts and Telecommunications
}

See next page for additional authors

Follow this and additional works at: https://arrow.tudublin.ie/engscheceart

\section{Recommended Citation}

Qiang Wu, Yuliya Semenova, Binbin Yan, Youqiao Ma, Pengfei Wang, Chongxiu Yu and Gerald Farrell, "Fiber refractometer based on a fiber Bragg grating and single-mode-multimode-single-mode fiber structure", Optics Letters, vol. 36, no. 12, pp. 2197-2199, 2011. doi:10.1364/OL.36.002197

This Article is brought to you for free and open access by the School of Electrical and Electronic Engineering at ARROW@TU Dublin. It has been accepted for inclusion in Articles by an authorized administrator of ARROW@TU Dublin. For more information, please contact arrow.admin@tudublin.ie, aisling.coyne@tudublin.ie, gerard.connolly@tudublin.ie.

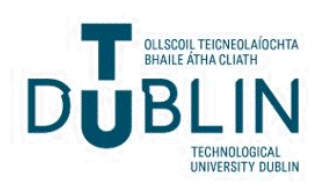


Authors

Qiang wu, Yuliya Semenova, Binbin Yan, Youqiao Ma, Pengfei Wang, Chongxiu Yu, and Gerald Farrell

This article is available at ARROW@TU Dublin: https://arrow.tudublin.ie/engscheceart/159 


\title{
Fiber refractometer based on an FBG and SMS fiber structure
}

\author{
Qiang $\mathrm{Wu}^{1^{*}}$, Yuliya Semenova ${ }^{1}$, Binbin Yan ${ }^{2}$, Youqiao Ma ${ }^{1}$, Pengfei Wang ${ }^{1}$, Chongxiu $\mathrm{Yu}^{2}$ and \\ Gerald Farrell $^{1}$ \\ ${ }^{1}$ Photonics Research Center, School of Electronic and Communications Engineering, Dublin Institute of Technology, Kevin \\ Street, Dublin 8, Ireland \\ ${ }^{2}$ Key Laboratory of Information Photonics and Optical Communications, Beijing University of Posts and \\ Telecommunications, Ministry of Education, P.O. Box 72 (BUPT), Beijing 100876, China \\ *Corresponding author: qiang.wu@dit.ie
}

Received Month X, XXXX; revised Month X, XXXX; accepted Month X, XXXX; posted Month X, XXXX (Doc. ID XXXXX); published Month X, XXXX

A refractive index (RI) sensor based on a novel fiber structure which consists of a singlemode-multimodesinglemode (SMS) fiber structure followed by a fiber Bragg grating (FBG) was demonstrated. The multimode fiber (MMF) in the SMS structure excites cladding modes within output singlemode fiber (SMF) and re-couple the reflected cladding Bragg wavelength to the input SMF core. By measuring the relative Bragg wavelength shift between core and cladding Bragg wavelengths, the RI can be determined. Experimentally we have achieved a maximum sensitivity of $7.33 \mathrm{~nm} / \mathrm{RIU}$ (RI unit) at RI range from 1.324 to 1.439 .

OCIS Codes: 060.2370, 060.2340

A Fiber Bragg grating (FBG) based sensor offers several advantages such as small size, fast response, immunity to electromagnetic interference, remote operation capability and capability facility for simultaneous multipoint measurements by an array of FBGs written in a single fiber, etc [1]. An FBG based refractometer is an attractive refractive index (RI) sensor due to the advantages cited above. An FBG based refractometer was firstly reported by Asseh et al in 1998 using an etched FBG as RI sensor [2]. In 2001, Schroeder et al proposed to use a side polished FBG to measure surrounding RI (SRI) [3] and a more detailed analysis based on etched D-shaped FBG refractometer was provided by Zhou et al in 2004 [4]. Recently Frazao et al proposed to use an FBG written in an $\mathrm{H}$-shaped fiber to simultaneously measure both temperature and RI [5]. A tilted FBG has been widely investigated as an RI sensor by utilizing the coupling between core mode and cladding modes [6-8]. More recently Han et al proposed to use a long period grating (LPG) to excite and re-couple the cladding mode of an ordinary FBG to simultaneously measure both RI and temperature [9]. This is a promising technique, but imprinting of an LPG will add fabrication complexity and extra cost to the refractometer. Previous investigations show that a singlemode-multimode-singlemode (SMS) fiber structure can excite and couple multiple modes to a singlemode fiber (SMF) [10-14]. In this paper we propose to use a SMS followed by an FBG imprinted SMF (SMS+FBG) to measure SRI. Compared to [9], our proposed technique has advantages of simple configuration and easy fabrication. More importantly the spectral response of an SMS fiber structure can be easily adjusted by selecting different types and length of the MMF. The proposed SMS+FBG refractometer structure is shown in figure 1.

In figure 1, an SMF fiber is fusion spliced to an MMF and followed by a fusion splice to an FBG imprinted SMF.
Both the SMF and MMF fibers in figure 1 have a step index profile. When the light injected from the input SMF into the MMF, multiple modes will be excited and will propagate within MMF. Assuming the field profile within the MMF as $\Psi_{\mathrm{m}}(\mathrm{r})$, the input field at the MMF can be written as:

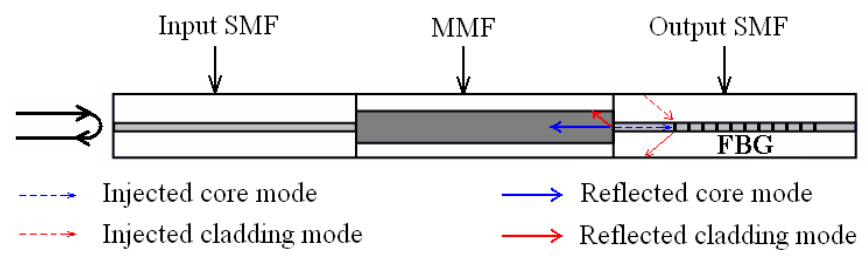

Fig. 1 Schematic of SMS+FBG refractometer

$$
E(r, 0)=\sum_{m=1}^{M} b_{m} \Psi_{m}(r)
$$

where $E(r, 0)$ is the core eigenmode of the input $\mathrm{SMF}, \Psi_{\mathrm{m}}(\mathrm{r})$ is $\mathrm{m}^{\text {th }}$ eigenmode of the MMF and $b_{m}$ is the excitation coefficient for each mode, which can be expressed as:

$$
b_{m}=\frac{\int_{0}^{\infty} E(r, 0) \Psi_{m}(r) r d r}{\int_{0}^{\infty} \Psi_{m}(r) \Psi_{m}(r) r d r}
$$

After propagation distance $z$ within the MMF section, the field can be express as:

$$
E(r, z)=\sum_{m=1}^{M} b_{m} \Psi_{m}(r) \exp \left(j \beta_{m} z\right)
$$

where $\beta_{m}$ is the propagation constant of $\mathrm{m}^{\text {th }}$ eigenmode within the MMF. For the light coupled from the MMF into the output SMF, a portion of the 
light enters the SMF core while the remaining portion is coupled into the SMF cladding. In this case the output SMF can be considered as a three layer structure where the medium surrounding the fiber cladding is the $3^{\text {rd }}$ layer of the fiber [15]. The coupling coefficients can be expressed as follows:

$$
c_{n}=\frac{\int_{0}^{\infty} E(r, z) \Phi_{n}(r) r d r}{\int_{0}^{\infty} \Phi_{n}(r) \Phi_{n}(r) r d r}
$$

where $\Phi_{n}(r)$ is $n^{\text {th }}$ mode within the output SMF $(n=1$ represents the core mode and $n>1$ represent cladding modes). Assuming the splice between the SMF and MMF is ideal, only $L P_{O_{m}}$ and $L P_{O_{n}}$ modes will be excited within the MMF and SMF respectively, due to the circular symmetry of the input field [13-14]. The calculated coupling coefficients for the first eleven modes to the output SMF are shown in figure 2.

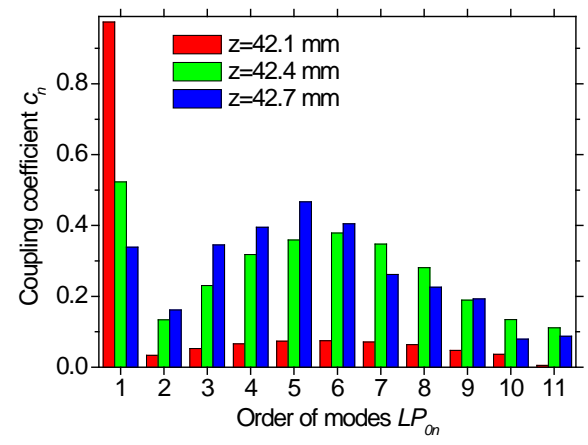

Fig. 2 Calculated coupling coefficients to the output SMF for different modes in the SMS structure as a function of MMF length

In this simulation, the MMF has core and cladding diameters of 104 and $125 \mu \mathrm{m}$ and refractive indices of 1.4446 and 1.4271 respectively. The SMF has a core and cladding diameters of 8.3 and $125 \mu \mathrm{m}$ and refractive indices of 1.449 and 1.445 respectively and the SRI is 1.33. The wavelength used in the simulation is $1550 \mathrm{~nm}$.

Figure 2 shows that at a particular wavelength, coupling coefficient $c_{n}$ is determined by the MMF length. By properly selecting the MMF length, a relatively high $c_{n}$ can be achieved for a particular cladding mode. When these modes arrive at the FBG, they will be reflected by the FBG and the reflected wavelength can be expressed by the following equation [9]:

$$
\lambda=2 n_{\text {eff }}(n) \Lambda
$$

where $\Lambda$ is the Bragg grating period, $n_{\text {eff }}(n)$ is the $\mathrm{n}^{\text {th }}$ effective RI of the output SMF ( $\mathrm{n}=1$ represents the core mode and $n>1$ represent cladding modes). As the SRI changes, the effective RI of the cladding modes will change but that of the core mode remains unchanged. Using a broadband source and monitoring the relative shift between the reflected wavelengths of selected cladding and core modes, the SRI can be determined.

Experiments based on the above structure were carried out. The single- and multimode fibers used in our experiment were SMF28 and AFS105/125Y respectively. The length of the MMF was $42.1 \mathrm{~mm}$. The FBG was imprinted in an SMF28 which had a grating length of $50 \mathrm{~mm}$ and reflectivity of $50 \%$. The distance between the end of the MMF section and beginning of the FBG was circa $5 \mathrm{~mm}$.

The transmission spectrum of an SMS fiber structure is shown in figure $3(\mathrm{a})$. It can be seen that there is a transmission peak at a wavelength circa $1540 \mathrm{~nm}$. The FBG used in our experiment has a core Bragg wavelength of $1545 \mathrm{~nm}$. When the light, for example from a broadband source, is injected from the FBG end (right hand side in Fig. 3(b)), the reflective spectrum has only one peak wavelength at circa $1545 \mathrm{~nm}$ which is the core Bragg grating wavelength. However if the light is injected from the MMF end (left hand side in Fig. 3(c)) there are multiple reflected wavelength peaks. This is because multiple modes excited in the MMF section propagate in both the core and cladding of the output SMF in the region where FBG is imprinted and both the core and cladding modes are reflected by the FBG and re-coupled to the MMF. The re-coupled light is transmitted through the MMF again and coupled back to the core of the input SMF. In Fig. 3(c) $\lambda_{0}$ is the core Bragg wavelength, $\lambda_{1}$ and $\lambda_{2}$ are cladding Bragg wavelengths corresponding to $3^{\text {rd }}$ and $5^{\text {th }}$ order cladding modes.

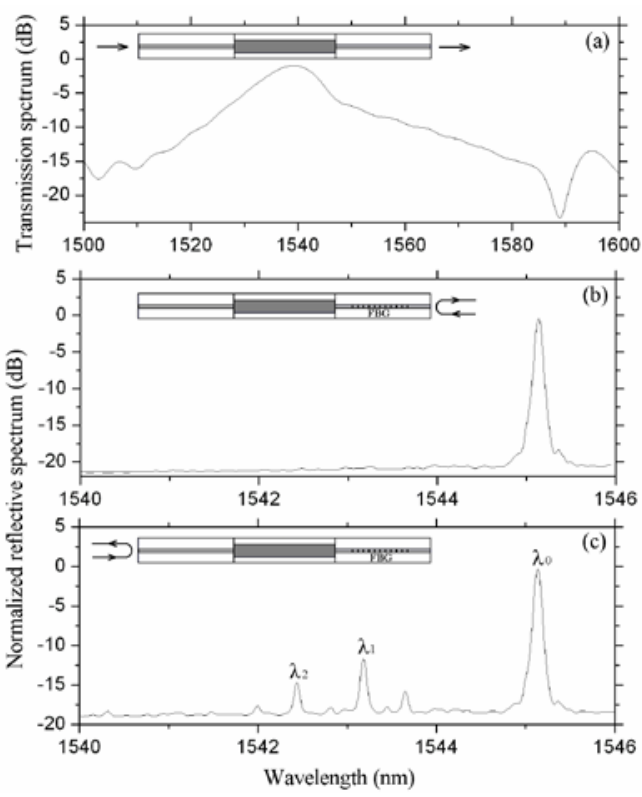

Fig. 3 Measured (a) transmission spectrum of the SMS fiber structure, (b) reflective spectrum of a single FBG and (c) reflective spectrum of SMS+FBG

Experimental investigations were carried out by immersing the SMS+FBG structure into liquids with different RI values. The reflective spectral responses 
corresponding to different SRI are shown in figure 4 for the reflected Bragg wavelengths of the core mode and two cladding modes.

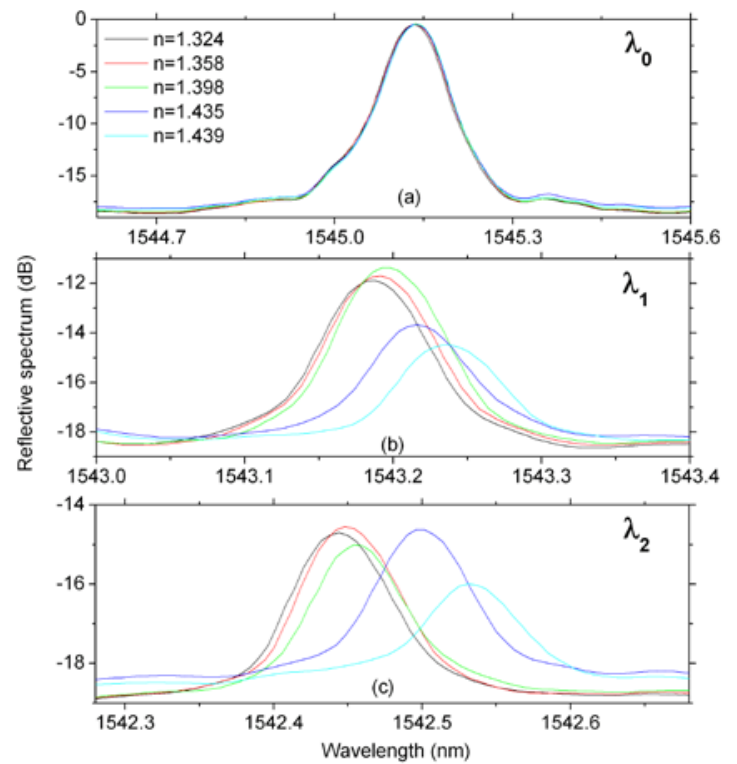

Fig. 4 Measured reflective spectral responses of (a) $\lambda_{0}$, (b) $\lambda_{1}$ and (c) $\lambda_{2}$ at different SRI

Figure 4 shows that as the SRI increases, the core Bragg wavelength remains unchanged (Fig 4(a)), but the cladding Bragg wavelengths experience red shift. This is due to the fact that as the SRI increases, the effective RI of the core mode remains unchanged, while the effective $\mathrm{RI}$ of $\mathrm{n}^{\text {th }}$ cladding modes increases with an increase of the SRI, resulting in the corresponding increase for the cladding Bragg wavelength. The measured relative wavelength shifts between core and cladding Bragg wavelengths vs. SRI is shown in figure 5(a).
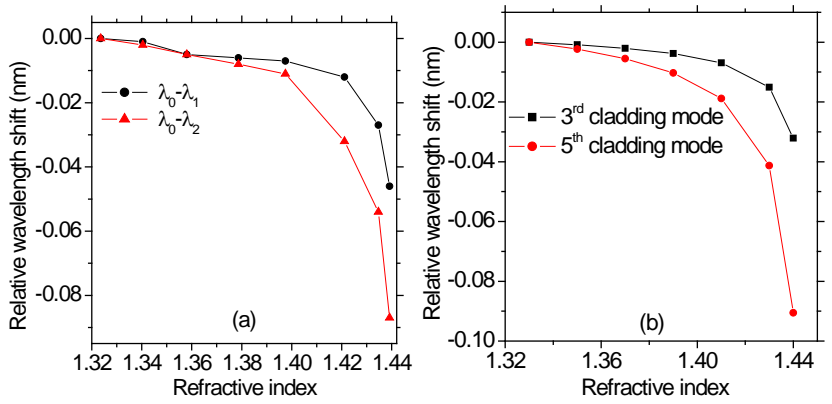

Fig. 5 (a) Measured and (b) simulated relative wavelength shift between core and cladding Bragg wavelengths vs. RI

Figure 5 shows that as the RI increases from 1.324 to 1.439 , there is $87 \mathrm{pm}$ and $46 \mathrm{pm}$ relative peak wavelength shift for $\lambda_{0}-\lambda_{2}$ and $\lambda_{0}-\lambda_{1}$ respectively. This result indicates that higher order cladding modes will have higher sensitivity to the change of SRI compared to lower order cladding modes. Figure 5(b) shows the simulated relative wavelength shift for $3^{\text {rd }}$ and $5^{\text {th }}$ order cladding modes vs. RI variations, which agrees well with the experimental results as shown in Fig. 5(a). In this simulation, the SMF fiber has the same parameters as above and the Bragg grating period $\Lambda$ is $534 \mathrm{~nm}$.

In conclusion we have proposed a novel RI sensor based on an SMS+FBG fiber structure. This structure utilizes MMF to excite cladding modes within an FBG imprinted SMF and re-couple reflected cladding Bragg wavelength to the input SMF core. By measuring the relative core-cladding Bragg wavelength shift, the RI can be determined. Experimentally we have achieved a maximum sensitivity of $7.33 \mathrm{~nm} / \mathrm{RIU}$ (RI unit) in the RI range from 1.324 to 1.439 . The sensitivity can also be enhanced by optimizing the parameters of the fiber used [16]. Finally it is important to point out that this work has more general applications, in that it is possible to use an SMS fiber structure instead of a LPG to couple cladding modes to a core mode.

This work was supported by Science Foundation Ireland under grant no. 07/SK/I1200, Irish Research Council for Science, Engineering and Technology, and Marie-Curie Actions under FP7.

\section{References}

1. A. D. Kersey, M. A. Davis, H. J. Patrick, M. LeBlanc. K. P. Koo, C. G. Askins, M. A. Putnam and E. J. Friebele, J. of Lightw. Techno., 15, 1442-1463, (1997)

2. A. Asseh, S. Sandgren, H. Ahlfeldt, B. Sahlgren, R. Stubbe, G. Edwall, Fiber and Integrated Optics, 17, 51-62, (1998)

3. K. Schroeder, W. Ecke, R. Mueller, R. Willsch, A. Andreev, Measu. Sci. \& Techno., 12, 757-764, (2001)

4. K. Zhou, X. Chen, L. Zhang and I. Bennion, Electr. Lett., 40, 232-234, (2004)

5. O. Frazao, T. Martynkien, J. M. Baptista, J. L. Santos, W. Urbanczyk, J. Wojcik, Opt. Lett., 34, 7678, (2009)

6. G. Laffont and P. Ferdinand, Meas. Sci. \& Techno., 12, 765-770, (2001)

7. C. Caucheteur, S. Bette, C. Chen, M. Wuilpart, P. Megret and J. Albert, Photon. Technol. Lett., 20, 2153-2155, (2008)

8. T. Guo, H. Y. Tam, P. A. Krug, J. Albert, Optics Express, 17, 5736-5742, (2009)

9. M. Han, F. W. Guo, Y. F. Lu, Optics Letters, 35, 399401, (2010)

10. Q. Wu, A. M. Hatta, Y. Semenova and G. Farrell, Applied Optics, 48, 5451-5458, (2009)

11. Q. Wu, Y. Semenova, P. Wang and G. Farrell, Optics Express, to be published

12. L. B. Soldano, E. C. M. Pennings, J. of Lightwave Technology, 13, 615-627, (1995)

13. Q. Wang, G. Farrell, and W. Yan, J. Lightwave Technol. 26, 512 (2008).

14. W. S. Mohammed, P. W. E. Smith, and X. Gu, Opt. Lett. 31, 2547 (2006).

15. M. Monerie, IEEE Journal of quantum electronics, vol. QE-18, 535-542, (1982)

16. A. Iadicicoo, A. Cusano, A. Cutolo, R. Bernini and M. Giordano, Photon. Technol. Lett., 16, 1149-1151, (2004) 
1. A. D. Kersey, M. A. Davis, H. J. Patrick, M. LeBlanc. K. P. Koo, C. G. Askins, M. A. Putnam and E. J. Friebele, "Fiber grating sensors", Journal of Lightwave Technology, vol. 15, no. 8, pp. 1442-1463, Aug. 1997

2. A. Asseh, S. Sandgren, H. Ahlfeldt, B. Sahlgren, R. Stubbe, G. Edwall, "Fiber optical Bragg grating refractometer", Fiber and Integrated Optics, vol. 17, no. 1, pp. 51-62, 1998

3. K. Schroeder, W. Ecke, R. Mueller, R. Willsch, A. Andreev, "A fibre Bragg grating refractometer", Measurement Science \& Technology, vol. 12, no. 7, pp. 757-764, 2001

4. K. Zhou, X. Chen, L. Zhang and I. Bennion, "High-sensitivity optical chemsensor based on etched D-fibre Bragg gratings", Electronics Letters, vol. 40, no. 4, pp. 232-234, 2004

5. O. Frazao, T. Martynkien, J. M. Baptista, J. L. Santos, W. Urbanczyk, J. Wojcik, "Optical refractometer based on a birefringent Bragg grating written in an H-shaped fiber”, Optics Letters, vol. 34, no. 1, pp. 76-78, 2009

6. G. Laffont and P. Ferdinand, "Tilted short-period fibre-Bragg-grating-induced coupling to cladding modes for accurate refractometry", Measurement Science \& Technology, vol. 12, pp. 765-770, 2001

7. C. Caucheteur, S. Bette, C. Chen, M. Wuilpart, P. Megret and J. Albert, "Tilted fiber Bragg grating refractometer using polarization-dependent loss measurement”, Photonics Technology Letters, vol. 20, no. 24, pp. 2153-2155, 2008

8. T. Guo, H. Y. Tam, P. A. Krug, J. Albert, "Reflective tilted fiber Bragg grating refractometer based on strong cladding to core recoupling”, Optics Express, vol. 17, no. 7, pp. 5736-5742, 2009

9. M. Han, F. W. Guo, Y. F. Lu, “Optical fiber refractometer based on cladding-mode Bragg grating”, Optics Letters, vol. 35, no. 3, pp. 399-401, 2010

10. Q. Wu, A. M. Hatta, Y. Semenova and G. Farrell, "Use of a SMS fiber filter for interrogating FBG strain sensors with dynamic temperature compensation", Applied Optics, vol. 48, pp. 5451-5458, 2009

11. Q. Wu, Y. Semenova, P. Wang and G. Farrell, "High sensitivity SMS fiber structure based refractometer - analysis and experiment", Optics Express, to be published

12. L. B. Soldano, E. C. M. Pennings, "Optical multi-mode interference devices based on self-imaging: principles and applications", Journal of Lightwave Technology, vol. 13, no. 4, pp. 615-627, 1995

13. Q. Wang, G. Farrell, and W. Yan, "Investigation on singlemode- multimode- singlemode fiber structure" , J. Lightwave Technol. 26, 512 (2008).

14. W. S. Mohammed, P. W. E. Smith, and X. Gu, "All-fiber multimode interference bandpass filter" , Opt. Lett. 31, 2547 (2006).

15. M. Monerie, "Propagation in doubly clad single-mode fibers", IEEE Journal of quantum electronics, vol. QE-18, no. 4, pp. 535-542, 1982

16. A. Iadicicoo, A. Cusano, A. Cutolo, R. Bernini and M. Giordano, "Thinned fiber Bragg gratings as high sensitivity refractive index sensor", Photonics Technology Letters, vol. 16, no. 4, pp. 1149-1151, 2004 